\title{
A EDUCAÇÃO A DISTÂNCIA NO BRASIL: conceitos e fundamentos
}

\author{
Distance education in Brazil: \\ concepts and foundations
}

\begin{abstract}
Marcio Mugnol
Professor da Faculdade Internacional de Curitiba (FACINTER), Curitiba, PR Brasil, e-mail: marciomugnol@yahoo.com.br
\end{abstract}

\section{Resumo}

Este texto tem por objetivo fazer uma análise da trajetória histórica da Educação a Distância (EAD) no Brasil. Procura destacar seus principais momentos no transcorrer do século XX e início do século XXI. Discute seus conceitos, seus fundamentos e a função desempenhada por ela na realidade social do Brasil. A EAD é apresentada como uma modalidade de ensino que acompanhou o desenvolvimento do sistema educacional brasileiro e, a partir de 1996, vem recebendo significativo apoio do Governo Federal que, por meio do Ministério da Educação, tem incentivado o seu crescimento, tanto na esfera púbica quanto privada. Iniciativas como a criação da Universidade Aberta do Brasil (UAB) são tidas como exemplos que demonstram o interesse governamental em constituir a EAD como uma modalidade de educação capaz de democratizar o acesso ao ensino superior.

Palavras-chave: Educação a distância. Instituições de ensino. Ministério da educação. Fundamentos da EAD. Cursos a distância.

Rev. Diálogo Educ., Curitiba, v. 9, n. 27, p. 335-349, maio/ago. 2009 


\section{Abstract}

This text aims to make an analysis of the Long Distance Learning (LDL) history in Brazil. It tries to focus on its principal moments along the twentieth century and the beginning of the twenty-first century. Its concepts and foundations are discussed, as well as its function in Brazil social reality. LDL is presented as a teaching modality that has been following the development of Brazilian educational system, and since 1966 has been receiving relevant support from the Federal Government that has encouraged its development through the Ministry of Education, both in public and private sphere. Initiatives like the creation of UAB (Universidade Aberta do BrasilBrazil Open University) are considered as examples that demonstrate government interest in constituting LDL as a teaching modality capable of democratizing access to higher education.

Keywords: Distance education. Teaching institutions. Ministry of education. LDL foundations. Distance learning.

\section{INTRODUÇÃO}

A Educação a Distância ao longo de sua história traçou uma trajetória de avanços e retrocessos. No início do século XX, tornou-se uma modalidade de ensino capaz de atender a todos os níveis, incluindo programas formais de ensino, aqueles que oferecem diplomas ou certificados e programas de caráter não formais, cujo objetivo é oferecer capacitação para a melhoria no desenvolvimento das atividades profissionais.

O número de instituições de ensino públicas e privadas que oferecem cursos nesta modalidade tem crescido significativamente no Brasil depois da publicação da Lei de diretrizes e Bases - LDB em 1996. Segundo dados da Associação Brasileira de Educação a Distância - ABED, o número de instituições que ofertam cursos superiores na modalidade de EAD cresceu $36 \%$ no período de 2004 a 2006. Passando de 166 para 225. O número de alunos cresceu 150\%, passando de 309.957 para 778.458 no mesmo período. ${ }^{1}$

Fonte: Anuário 2007 ABED, disponível em: <http://www.abed.com.br>. Acesso em: 15 jan. 2009. Associação Brasileira de Educação a Distância - ABED, é uma sociedade científica, sem fins lucrativos, que tem como finalidades: o estudo, a pesquisa, o desenvolvimento, a promoção e a divulgação da educação a distância.

Rev. Diálogo Educ., Curitiba, v. 9, n. 27, p. 335-349, maio/ago. 2009 
Apesar do progresso recente da educação a distância, muitos dos seus principais pontos estratégicos ainda não foram discutidos com a profundidade necessária. Pode-se destacar como pontos ainda controversos na EAD, os seus objetivos, a forma de transmissão, os provedores da tecnologia, a população-alvo dos cursos ofertados, a formação e organização dos projetos pedagógicos, os métodos de avaliação de aprendizagem, entre tantos outros. São também carentes de regulamentação o sistema de acompanhamento do aprendizado dos alunos, a formação dos professores, as diferentes metodologias utilizadas, a avaliação do resultado do processo de ensino aprendizagem, os critérios de credenciamento de novas instituições e autorização de novos cursos, entre outros.

A discussão desses tópicos exige um regate histórico do caminho percorrido pela educação a distância que contemple, sobretudo, uma análise detalhada do seu conceito fixado ao longo de lentos e sinuosos traços de desenvolvimentos.

Os avanços tecnológicos tornaram mais visíveis as possibilidades de desenvolvimento da EAD, favorecendo, ainda no final do século XIX e no início do século XX, a multiplicação de iniciativas em muitos países da Europa, África e América. Países como Suécia, Inglaterra, França, bem como, Canadá e EUA e mais recentemente o Brasil, são considerados grandes propulsores da metodologia da educação a distância.

\section{FUNDAMENTOS DA EDUCAÇÃO A DISTÂNCIA}

A forma inicial de oferta dos cursos a distância era a correspondência e tinha como finalidade ampliar a oferta de oportunidades educacionais, permitindo que as camadas sociais menos privilegiadas economicamente pudessem participar do sistema formal de ensino, sobretudo da educação básica, uma vez que as preocupações iniciais da EAD estavam focadas neste nível de ensino e em cursos preparatórios para o trabalho.

A exemplo do que acontece nos dias atuais, as iniciativas de EAD eram tidas como de baixo nível, faziam parte dos ideais de democratização do ensino, mas sofriam preconceitos e tinham o estigma de ser um ensino destinado às massas, à população marginalizada, para compensar os atrasos educativos provocados pelo modelo capitalista de desenvolvimento.

Os cursos a distância, aliás, a educação a distância teve grande impulso com o surgimento do rádio, do telégrafo e do telefone. Estes equipamentos caracterizaram o início da era dos meios modernos de comunicação.

O desenvolvimento das telecomunicações com meios interativos, a relativa popularização do computador e da internet, proporcionaram novas

Rev. Diálogo Educ., Curitiba, v. 9, n. 27, p. 335-349, maio/ago. 2009 
perspectivas se constituindo em ferramentas importantes para a contínua evolução da EAD, sobretudo após na segunda metade do século XX.

Um dos marcos históricos da Educação a distância foi a criação da Universidade Aberta de Londres em 1970, a Open University, que contribuiu decisivamente para o desenvolvimento de métodos e técnicas que serviram para caracterizar os diferentes modelos de EAD existentes. Além disso, contribuiu também para o desenvolvimento de tecnologias que deram mais solidez aos processos educacionais a distância e para a utilização massiva da mídia.

Seguindo o exemplo da Inglaterra, outros países criaram instituições para desenvolver projetos formais de educação a distância, assim surgiu a Universidade Nacional de Educação a Distância, (UNED) em Madri (1972), que pode ser caracterizada como uma das iniciativas de maior sucesso e que serviu de modelo para outros países.

A partir da metade do século XX, com o surgimento das primeiras instituições educacionais voltadas para a EAD e com o desenvolvimento acentuado das tecnologias de comunicação, ocorreu um despertar do interesse de estudiosos e pesquisadores, que procuraram conceituar a EAD e descrever com segurança as suas metodologias.

Entre estes pesquisadores está Desmond Keegan (1980) que identifica alguns elementos-chave dos processos educacionais à distância, tais como:

- distância física entre professores e alunos;

- $\quad$ influência de uma organização educacional;

- uso da mídia para interligar professores e alunos;

- $\quad$ troca de comunicação bidirecional;

- aprendizes vistos como indivíduos, ao invés de grupos de alunos.

A distância física entre professores e alunos, a comunicação com o uso da mídia, são inovações trazidas pela EAD que se constituem num desafio para as instituições de ensino. Exigem investimentos em tecnologia avançada para a mediação e ao mesmo tempo mudança na cultura dos professores e alunos que tem como parâmetro o modelo pedagógico presencial, caracterizado pela presença física de professores e alunos num mesmo tempo e espaço.

Mesmo com o crescimento exponencial conquistado no final do século XX e início do século XXI, com a criação de instituições especializadas na metodologia e no gerenciamento de cursos a distância, no entender de Keegan (1996) "a literatura existente sobre o assunto revela um panorama fragmentado, não consolidado e carente de fundamentação teórica e trabalhos de pesquisa direcionados, capazes de explicar os principais pontos controversos na descrição dos fundamentos da educação a distância”.

Rev. Diálogo Educ., Curitiba, v. 9, n. 27, p. 335-349, maio/ago. 2009 
O processo educacional à distância é reconhecido como centrado no aluno e mediado pelas tecnologias da sociedade da informação, fato esse que leva à necessidade de se investigar como alunos e instrutores, com o uso das novas tecnologias, podem colaborar para gerar novos conhecimentos.

Nos primeiros anos da década de 90, um grupo de educadores europeus, com o objetivo de aprofundar os conhecimentos sobre treinamento a distância na União Europeia, elaborou um estudo do qual resultou um relatório, apresentado em 1997 e denominado VOCTADE - Vocational Education and Training (VET) at a distance in the European Union. Representou um apanhado das diversas metodologias utilizadas pelas instituições de ensino que trabalham com a EAD na União Europeia. O relatório foi aceito como um trabalho de cunho científico pelos profissionais do meio acadêmico, colaborando para o aprofundamento dos conhecimentos sobre esta modalidade de ensino.

O relatório em questão, além das contribuições de cunho teórico e metodológico, apresentou universidades, colégios, centros de treinamento e universidades abertas, como as instituições promovedoras de cursos de educação a distância, os quais distribuem os alunos em grupos ou individualmente e diferenciam os cursos considerando a distribuição ou não de material didático pré-preparado.

Muitos autores de renome no meio acadêmico serviram de referencial para os estudos sintetizados no relatório. Pode-se destacar John Daniel (Reino Unido), Borge Holmberg (Suécia), Desmond Keegan (Irlanda), Otto Peters (Alemanha) e Benedetto Vertecchi (Itália), Michael Moore (Reino Unido), John Baath (Suécia), David Sewart (Reino Unido) e Charles Wedemeyer (EUA), pesquisadores que se dedicam ao estudo e conceituação da educação a distância e suas metodologias.

Desmond Keegan (1996), um dos principais teóricos da EAD, destaca em suas obras que o processo educacional a distância tem a seguintes características:

- $\quad$ sofre influência de uma organização educacional no planejamento, preparação do material de ensino e na provisão de serviços de suporte aos alunos;

- distância física entre professores e alunos;

- $\quad$ utilização da mídia - impressos, áudio, vídeo ou computador - para mediar ações educativas entre professores e alunos no desenvolvimento do conteúdo do curso;

- comunicação bidirecional, de forma que o aluno pode se beneficiar de um diálogo mais estreito com o professor;

- quase permanente ausência de grupos de aprendizagem presenciais, com a possibilidade de encontros, face a face ou através de meios eletrônicos, sendo os estudos individuais responsáveis por completar as necessidades e propósitos de socialização.

Rev. Diálogo Educ., Curitiba, v. 9, n. 27, p. 335-349, maio/ago. 2009 
A existência de materiais didáticos de qualidade para a educação a distância, a mediação tecnológica dos meios de comunicação e informação, são atributos que se colaboram para o bom desempenho do papel do professor. Aos alunos são atribuídas maiores responsabilidade sobre a própria formação, traduzida esta, em maturidade intelectual para estudos individuais e disciplina para o cumprimento das tarefas propostas pelos professores.

Landin (1997, p. 9) diz que "com a grande expansão da EAD no final dos anos 60 e na década de 70, estudiosos desta modalidade educativa apresentam suas contribuições, estas foram classificadas por Keegan (1983) em três grupos," assim distribuídos:

- $\quad$ as teorias da autonomia e independência, arguidas por Charles Wedemeyer (EUA) e Michael Moore (Reino Unido), que refletem, como componente essencial, a independência do aluno;

- o trabalho de Otto Peters (Alemanha) em uma teoria da industrialização, que reflete a tentativa de visualizar o campo da educação a distância como uma forma industrializada de ensinamento e aprendizagem;

- $\quad$ a terceira corrente integra as teorias de interação e comunicação formuladas por Baath (Suécia), Sewart (Reino Unido) e Börje Holmberg (Suécia), Daniel \& Marquis (Reino Unido).

A metodologia aplicada na EAD prima pela conscientização dos alunos sobre o seu papel no resultado das atividades acadêmicas para o seu aprendizado. Os conceitos de autonomia e independência, arguidos por Keegan (1996), têm como fundamento a aprendizagem, que por sua vez remete à criação de oportunidades para que a mesma possa acontecer.

As oportunidades de aprendizagem, por sua vez, implicam na criação de meios pelos quais elas poderão acontecer efetivamente, e no caso da EAD os principais meios a serem considerados são: comprometimento e responsabilidade do aluno, orientação e apoio dos professores disponível em todos os momentos, a utilização compartilhada de métodos e meios de transmissão das informações, o respeito às diferenças individuais com a utilização de métodos capazes de respeitar o ritmo da aprendizagem de cada estudante.

Corroborando com esta discussão e tendo em vista que a educação a distância no Brasil é fundamentalmente direcionada para alunos da idade adulta, Martins (2005), destaca que:

- $\quad$ os adultos são, por definição, autorresponsáveis e, assim, têm o direito de decidir sobre o que e como será sua educação;

Rev. Diálogo Educ., Curitiba, v. 9, n. 27, p. 335-349, maio/ago. 2009 
- há que se considerar as diferenças individuais sobre todo o campo dos estilos cognitivos;

- $\quad$ se as instituições não apóiam as demandas de aprendizagem dos adultos, estes conseguirão apoiar-se a si mesmos.

A educação a distância se desenvolve através da articulação de atividades pedagógicas capazes de desenvolver os aspectos afetivo, psicomotor e cognitivo dos estudantes. Para isso, utiliza-se de formas de comunicação não contígua, que independem do tempo e do lugar onde se encontram os atores do processo, isso a torna interessante para alunos adultos que tem compromisso com o mercado de trabalho. Landin (1997, p. 14), diz que "Holmberg é o importante e reconhecido teórico da EAD e apresenta sua teoria como um método de conversação didática guiada." Nas palavras do próprio autor "o sistema a distância implica estudar por si mesmo, mas o aluno não está só; vale-se de um curso e de interação com instrutores e com uma organização de apoio. Produz-se, assim, uma espécie de diálogo em forma de tráfego de mão dupla" (LANDIN, 1997, p. 14).

Otto Peters (2001), um dos pesquisadores citados no relatório VOCTADE de 1997, ao escrever sobre teoria da industrialização, considerou que ensino a distância incorpora os métodos do trabalho industrial. Martins (2005) resumiu suas proposições da seguinte forma:

- $\quad$ os estudos a distância são uma realidade em função da produção do material em escala industrial. O material é preparado por uma equipe de especialistas de diversas áreas. Isto significa uma mudança radical nas funções docentes tradicionais;

- planejamento do curso, a organização racional de todo o processo e a formatação das fases se assemelha à produção industrial;

- a preocupação de um contínuo controle, como a sistematização de contínuas avaliações no processo e do produto da EAD, objetiva a otimização do tempo e do trabalho dos recursos humanos e;

- a centralização e monopolização da produção tornam esse sistema economicamente rentável.

Considerando as discussões sobre a industrialização da educação na modalidade a distância, não se pode deixar de analisar os resultados efetivos alcançados por ela sob o ponto de vista dos alunos. Um dos quesitos indispensáveis

Rev. Diálogo Educ., Curitiba, v. 9, n. 27, p. 335-349, maio/ago. 2009 
para essa análise é a capacidade e habilidade dos alunos se projetarem socialmente em uma comunidade, tanto do ponto de vista acadêmico, dando continuidade aos seus estudos, quanto do ponto de profissional, tendo condições de desenvolver suas atividades laborais com competência.

Há que se considerar as diferenças sociais e culturais dos estudantes, uma vez que a educação a distância, com a utilização de meios de comunicação de massa, atinge público de regiões diferentes dentro de um mesmo país ou até mesmo países diferentes. Assim, torna-se importante definir de forma clara os objetivos dos cursos de EAD, tendo sempre a intenção de realizar uma atividade capaz de interferir positivamente na sociedade.

A estrutura administrativa da EAD, criada pelo Ministério da Educação (MEC), com a criação de uma secretaria específica para EAD, manuais de avaliação e regras próprias para credenciamento de Instituições, autorização e reconhecimento de cursos, tem feito com que a educação a distância se desenvolva em paralelo com a Educação Presencial.

Porém, existe uma perspectiva da convergência das duas modalidades, contando com um fator que as duas têm em comum, ou seja, a necessidade de utilização das novas tecnologias de informação e de comunicação para o desenvolvimento das atividades educativas. Assim sendo, torna-se cada vez maior o desafio de criar instrumentos de gestão do sistema de ensino que propiciem a melhoria da qualidade do ensino ofertado, bem como, a estruturação harmoniosa da EAD na realidade educacional brasileira.

Segundo Landim (1997, p. 9):

As bases teóricas da Educação a distância ainda são frágeis, porque, realmente, não é fácil estabelecer fundamentos neste campo, o que se explica, em parte, certamente, pela falta de um estudo de conjunto das variadas experiências, raramente mal sucedidas, aliás, que se espalham em dezenas de países, cada qual com suas peculiaridades, interesses, conveniências e objetivos, não se tendo chegado, ainda, a envidar esforços nacionais ou internacionais para embasamento teórico das experiências realizadas separadamente.

Os pressupostos teóricos da educação a distância, ainda carentes de maior aprofundamento, segunda a mesma autora, retomam a teoria da autonomia e independência; a teoria da industrialização e a teoria da interação e da comunicação. São essas teorias que procuram fundamentar solidamente a EAD. Já no que se refere ao conceito de educação a distância.

Niskier (2000, p. 49), diz que:

Rev. Diálogo Educ., Curitiba, v. 9, n. 27, p. 335-349, maio/ago. 2009 
A EAD tornou-se a modalidade fundamental de aprendizagem e ensino, no mundo inteiro. Antes cercada de mistério, hoje é até mesmo reivindicada por sindicatos poderosos, no Brasil, onde o seu prestígio cresce de forma bastante visível. Parte-se de um conceito extremamente simples: alunos e professores separados por uma certa distância e, as vezes pelo tempo. A modalidade modifica aquela velha idéia de que, para existir ensino, seria sempre necessário contar com a figura do professor em sala e de um grupo de estudantes.

Percebe-se a dificuldade para se chegar a um consenso sobre a definição de educação a distância e, obviamente, essa dificuldade está diretamente relacionada ao fato de existir uma carência na definição de seus fundamentos. Holmberg (1985), autor que coloca como base dos fundamentos da EAD a teoria da interação e da comunicação, define-a dizendo que:

A expressão "educação à distância" cobre as distintas formas de estudo em todos os níveis que não se encontram sob a contínua e imediata supervisão dos tutores, presentes com seus alunos na sala de aula, mas, não obstante, se beneficiam do planejamento, orientação e acompanhamento de uma organização tutorial.

Já Moore e Kearsley (1996) referem-se a essa modalidade não como educação, mas sim como ensino, dizendo que:

O ensino a distância é o tipo de método de instrução em que as condutas docentes acontecem à parte das discentes, de tal maneira que a comunicação entre o professor e o aluno se possa realizar mediante textos impressos, por meios eletrônicos, mecânicos ou por outras técnicas.

A diversidade de conceitos de educação a distância fomenta a discussão dos pesquisadores da área em torno de alguns termos, como por exemplo: tempo; distância; educação; ensino; entre outros, que estão presentes na maioria das definições.

Enquanto estas discussões vão sendo aprofundadas pelos pesquisados, as instituições de ensino superior que trabalham com educação a distância procuram organizar seus sistemas de gestão em função de um referencial de divisão do trabalho.

Rev. Diálogo Educ., Curitiba, v. 9, n. 27, p. 335-349, maio/ago. 2009 
Contam com o uso intensivo dos meios técnicos e tecnológicos na preparação dos materiais didáticos distribuídos para grandes quantidades de alunos espalhados por todo o território nacional. Aplicam técnicas de produção e distribuição de materiais em escala industrial, buscam otimizar os recursos humanos, físicos, financeiros e tecnológicos de que dispõem.

\section{EVOLUÇÃO DA EDUCAÇÃO A DISTÂNCIA NO BRASIL}

As primeiras iniciativas em educação a distância no Brasil se deram por meio de cursos por correspondência, o rádio e televisão foram usados como meios de apoio. Em meados dos anos 90, com a disseminação das tecnologias de informação e de comunicação, começam a surgir programas oficiais e formais de EAD incentivados pelas secretarias de educação municipais e estaduais, algumas iniciativas isoladas e outras em parceria com as universidades.

Os primeiros programas formais, criados sob a ótica da regulamentação da década de 90, eram voltados para a Formação Continuada de Professores da Rede Pública. São exemplos dessas iniciativas o Projeto Nave em São Paulo (ALMEIDA, 2001); o Projeto Virtus em Recife (NEVES; CUNHA 2002); o Projeto do NIED UNICAMP realizado em parceria com a Universidade Estadual de Londrina e a Universidade Estadual de Maringá (VALENTE, 2000).

As iniciativas de oferta de cursos de Lato Sensu, cursos de extensão e cursos livres marcam o início da educação em ambientes virtuais de aprendizagem no Brasil.

A educação a distância no Brasil tem sido objeto de pesquisas e trabalhos realizados nesta última década. As instituições que se dedicam à EAD receberam a contribuição teórica, no período de 1996 até 2006, de importantes nomes, como por exemplo, Landim (1997), Niskier (2000), Nunes (1998), Belloni (1999), Valente (2000), Martins (2005), Neves e Cunha (2000) e outros autores citados no número especial da Revista Em Aberto (1996). Na base do desenvolvimento da educação a distância tem-se a preocupação constante com o acesso a educação de quem não teve a oportunidade de estar presente na escola no tempo e no espaço considerados ideais para a educação escolar presencial.

A partir da segunda metade do século XX, em decorrência da expansão e das novas abordagens para a educação a distância, cresceu significativamente o número de pesquisadores dedicados aos estudos da $\mathrm{EAD}$, discutindo-se, entre outros aspectos, suas diferentes interfaces, modos de distribuição, metodologia e forma de interação com os alunos. Começou, também, a consolidar-se um processo legislativo resultante de uma política de EAD mais

Rev. Diálogo Educ., Curitiba, v. 9, n. 27, p. 335-349, maio/ago. 2009 
consistente, que almejava responder à exigência da expansão desta modalidade de ensino. Esse é o ponto que mais tem exigido atenção dos pesquisadores e profissionais envolvidos com educação a distância.

A partir da Lei n. 9.394/96, de 20 de dezembro de 1996, que estabelece as Diretrizes e Bases da Educação para todos os níveis de ensino (LDB), o ensino a distância, conforme dispõe o parágrafo $4^{\circ}$, do inciso IV, do artigo 32, passa a ser definido como uma modalidade utilizada para "complementação da aprendizagem ou em situações emergenciais"; e segundo o inciso 2, do artigo 87, cada município deve ser responsável por "prover cursos presenciais ou a distância aos jovens e adultos insuficientemente escolarizados."

O artigo 80 da mesma lei estabelece que "o poder público incentivará o desenvolvimento e a veiculação de programas de ensino a distância, em todos os níveis e modalidades de ensino e de educação continuada" (BRASIL, 1996).

O Plano Nacional de Educação, exigido pela LDB e que passou a vigorar em janeiro de 2001, com a aprovação da Lei 10.172/01, no capítulo que aborda a educação a distância e as Tecnologias Educacionais, refere-se a essa modalidade de ensino "como um meio auxiliar de indiscutível eficácia" para enfrentar "os déficits educativos e as desigualdades regionais".

O Decreto n. 5.622, de 19 de dezembro de 2005, estabeleceu o reconhecimento no sistema oficial de ensino dos cursos ofertados na modalidade por Instituições credenciadas pelo MEC. Com isso expande-se o processo de produção de conhecimento acerca da EAD no Brasil e novos projetos de cursos começam a ser desenvolvido, propondo-se inicialmente a atender interesses e necessidades específicas de formação de professores da Educação Básica e da Educação Superior.

Assim, torna-se necessário o desenvolvimento de um sistema normativo capaz de regulamentar esta modalidade de ensino integrando-a com a Educação Presencial, bem como, com a Educação Semipresencial, respeitando as particularidades de cada modalidade.

A entrada do século XXI caracterizou o fim das iniciativas particularizadas no campo da EAD. Deu início a uma era de amplos debates sobre esta modalidade, muito embora uma parte significativa da comunidade educacional continue considerando-a como uma modalidade diminuída de ensino e sem qualidade suficiente para ser equiparada à educação presencial.

O Ministério da Educação tem dedicado atenção a esta modalidade de ensino e vem publicando uma série de portarias normativas que estão servindo de fonte legal para demarcar os espaços, as formas de atuação das instituições e as características dos cursos.

Paralelo às iniciativas no campo da normatização legal, aprofundase o desenvolvimento e a utilização das tecnologias de comunicação e informação, inclusive com o desenvolvimento de equipamentos tecnológicos e softwares

Rev. Diálogo Educ., Curitiba, v. 9, n. 27, p. 335-349, maio/ago. 2009 
especialmente voltados para a educação a distância. Contudo, não passou despercebido aos pesquisadores a necessidade de voltar a atenção para a realidade sócio-econômica da América latina, sobretudo no que se refere à igualdade de acesso a informação e diferenças regionais. Especialmente para o Brasil que, por suas características sociais e extensão territorial, tem desenvolvido metodologias de EAD e estruturas administrativas diferenciadas da maioria dos outros países latino americanos, Estados Unidos e Europa.

Essas diferenças ficam evidentes quando comparamos as primeiras iniciativas de educação a distância, realizadas ainda por correspondência. A metodologia de EAD que tinha como objeto a aprendizagem por correspondência, que era utilizada antes do crescimento das tecnológicas aplicadas à educação e trabalhava com alunos de forma isolada, tornou-se tradição em países europeus e na América do Norte. No Brasil, como em outros países da América Latina, o ensino por correspondência foi acompanhado e em muitos casos superado por metodologias que utilizavam a radio-difusão ou tele-difusão, estes meios de comunicação sempre vistos com muita simpatia pela população brasileira.

O surgimento do computador como meio mais rápido para transportar a palavra escrita mudou não só o veículo de distribuição do ensino, mas a forma de mediação. A multimídia, que trabalha com as múltiplas linguagens (sonora, audiovisual e iconográfica), amplia as possibilidades de ensino aprendizagem e pode, desde que adequadamente projetada, atender a uma demanda social por educação.

Os fatores econômicos impõem diferentes alternativas, visto que a grande maioria dos países latino-americanos não desenvolveu suficientemente a sua capacidade tecnológica e não produz equipamentos eletrônicos que possam ser adquiridos pela maioria da população. Por isso, se torna necessário a utilização de meios de comunicação capazes de atingir grandes quantidades de pessoas, associados a tecnologias interativas e metodologias colaborativas.

O governo brasileiro iniciou certa tradição ao utilizar a rede de emissoras de rádio para a distribuição de programas educativos e culturais. Meio de alta agregação cultural, o rádio tem a capacidade de ser um veículo de amplo espectro social; continua a atingir todas as camadas sociais e níveis etários.

A partir do final da década de 1960, a televisão ampliou a comunicação, e a transformou, consolidando os meios audiovisuais. Foram várias as iniciativas governamentais para criar emissoras e redes de televisão educativa, destinando-se às redes comerciais apenas um percentual de sua programação para eventos de alcance educativo. Os programas Telecurso Primeiro e Segundo Grau formaram brasileiros em todas as regiões que recebiam a sua transmissão, propiciando que a educação a distância não formal resgatasse a autoestima de brasileiros e os qualificasse para novos projetos educacionais e profissionais.

Rev. Diálogo Educ., Curitiba, v. 9, n. 27, p. 335-349, maio/ago. 2009 
A trajetória histórica da educação a distância no Brasil revela um crescimento lento e sinuoso desta modalidade de ensino. Também deixa clara a existência de problemas que dificultaram e ainda continuam dificultando a criação de um sistema sólido de educação a distância, capaz de atender as expectativas do país e corrigir a dívida social com a educação.

O governo, a partir da década de 70, criou uma série de programas cujo objetivo era alavancar as iniciativas de educação a distância, podemos citar como exemplo o Programa Nacional de Tecnologias Educacionais, o Projeto Minerva envolvendo mais de 1200 emissoras de rádio, a TV escola de São Luís do Maranhão, a TV Universitária de Recife, a TVE do Rio de Janeiro, a TV Cultura em São Paulo, o projeto FEPLAN no Rio Grande do Sul, o IRDEB na Bahia e o Projeto SACI no Rio Grande do Norte. Estes são exemplos de iniciativas que não foram levadas a diante e a maioria desapareceu logo depois de ter sido criada. Por tudo o que foi exposto, percebe-se que a dificuldade de alavancar as iniciativas de EAD no Brasil se deve, sobretudo a:

- a implantação de projetos-piloto sem o adequado planejamento para continuidade;

- $\quad$ falta de critérios para avaliação dos programas implantados;

- iniciativas isoladas incapazes de criar uma memória sistematizada dos programas desenvolvidos;

- $\quad$ inexistência de avaliações das iniciativas;

- $\quad$ encerramento dos programas sem qualquer prestação de contas sobre os resultados e os recursos públicos investidos;

- $\quad$ indefinição da estrutura institucional para a gestão centralizada das iniciativas;

- projetos desvinculados da realidade, desconexos com os rumos do desenvolvimento econômico e político do país;

- baixo desenvolvimento tecnológico e carência de ferramentas de gestão das iniciativas;

- desconhecimentos dos potenciais da EAD e de suas exigências;

- $\quad$ administração das iniciativas por pessoas sem a necessária qualificação para as funções;

A Lei de Diretrizes e Bases da Educação Nacional de 1996, além de apresentar como fundamento os princípios da flexibilidade e da avaliação, apresenta, também, o princípio do respeito às iniciativas inovadoras, facultando a abertura de instituições e cursos em caráter experimental. Ao mesmo tempo, incentiva claramente a modalidade de educação a distância (EAD) que, a partir de então, passou a ser

Rev. Diálogo Educ., Curitiba, v. 9, n. 27, p. 335-349, maio/ago. 2009 
desenvolvida quase que exclusivamente pela iniciativa privada, tornando-se a modalidade de ensino que mais cresce no país, e que, desde então, tem sido objeto de discussão por parte dos estudiosos, das autoridades educacionais, das instituições de ensino, dos professores, dos alunos e da sociedade de modo geral.

O Ministério da Educação (MEC), em última instância o responsável pela educação no Brasil, tem se posicionado como um órgão regulador que define as políticas e diretrizes, que elabora os instrumentos e faz a avaliação do sistema.

\section{REFERÊNCIAS}

ALMEIDA, M. E. B. Formando professores para atuar em ambientes virtuais de aprendizagem. In: ALMEIDA, F. J. (Coord.). Projeto Nave, educação a distância: formação de professores em ambientes virtuais e colaborativos de aprendizagem. São Paulo: [s. n.], 2001. p. 79-82.

BELLONI, M. L. Educação a distância. Campinas: Autores Associados, 2001. BRASIL. Leis e Diretrizes e Bases da Educação Nacional. Decreto n. 5.622, de 19 de dezembro de 2005. Regulamenta o art. 80 da Lei 9.394/96, 20 dez. 1996. Estabelece as diretrizes e bases da educação nacional. Diário Oficial da União, Brasília, ano 134, n. 248, p. 27833-27841, dez. 2005. Disponível em: <http:// portal.mec.gov.br/seed/arquivos/pdf/dec_5622.pdf>. Acesso em: 15 jan. 2009.

BRASIL. Poder Legislativo. Institui o Sistema Nacional de Avaliação da Educação Superior - SINAES e dá outras providências. Lei 10.861 de 14 de abril de 2004. Diário Oficial da União, Brasília, n. 147. 2004. Disponível em: <http://www.planalto.gov.br/ccivil_03/_ato2004-2006/2004/Lei/ L10.861.htm>. Acesso em: 15 jan. 2009.

FIORENTINI, L. M. R.; MORAES, R. de A. (Org.). Linguagens e interatividade na educação a distância. Rio de Janeiro: DP\&A, 2003.

HOLMBERG, B. Educación a distancia: situación y perspectivas. Buenos Aires: Kapeluz, 1985.

KEEGAN, D. Fundations of distance education. 3rd ed. London: Routledge, 1996.

LANDIM, C. M. das M. P. F. Educação a distância: algumas considerações. Rio de Janeiro: Edição do Autor, 1997.

MARTINS, O. B. Fundamentos da educação a distância. Curitiba: IBPEX, 2005.

Rev. Diálogo Educ., Curitiba, v. 9, n. 27, p. 335-349, maio/ago. 2009 
MOORE, M.; KEARSLEY, G. Distance education: a systems view. Belmont: Wadsworth Publishing Co., 1996.

NISKIER, A. Educação a distância: a tecnologia da esperança. 2. ed. São Paulo: Loyola, 2000.

NEVES, A.; CUNHA FILHO, P. Virtus: uma proposta de comunidades virtuais de estudos. In: NEVES, A.; CUNHA FILHO, P. C. (Org.). Projeto virtus: educação e interdisciplinaridade na ciberespaço. Recife: Anhembi Morumbi, 2000. p. 21-32.

NUNES, I. B. Noções de educação a distância. Revista Educação a Distância, Brasília, v. 3, n. 4/5, p. 7-25, 1998.

PETERS, O. Didática do ensino a distância: experiências e estágios da discussão numa visão internacional. Rio Grande do Sul: Unisinos, 2001.

REVISTA EM ABERTO. Brasília: MEC/INEP, 1996.

VALENTE, J. A. Educação a Distância: uma oportunidade para mudança no ensino. In: MAIA, C. (Org.). EAD.BR Educação a distância no Brasil na era da Internet. São Paulo: Anhembi Morumbi, 2000. p. 97-122.

Recebido:14/03/2009

Received: 03/14/2009

Aprovado: 02/04/2009

Approved: 04/02/2009

Revisado: 21/07/2009

Reviewed: $07 / 21 / 2009$

Rev. Diálogo Educ., Curitiba, v. 9, n. 27, p. 335-349, maio/ago. 2009 